\title{
Gastrointestinale und biliäre Parasitosen - Update
}

\author{
Christoph Beglinger
}

\section{Übersicht}

Einleitung

Protozoen

Helminthen

\section{Einleitung}

Viele parasitäre Infektionen bleiben über längere Zeit undiagnostiziert, weil sie oft unspezifische Symptome verursachen, aber auch weil nicht daran gedacht wird. Parasitäre Darmerkrankungen sind bei uns selten, was ein Grund für eine oft verzögerte Diagnosestellung sein kann. Zudem werden parasitäre Erkrankungen in der Regel mit subtropischen oder tropischen Regionen assoziiert. Die heutige Mobilität mit häufigen Auslandsreisen, globale Migration sowie Import von tropischen Früchten erzeugen jedoch neue Rahmenbedingungen, sodass parasitäre Krankheiten auch bei uns häufiger vorkommen. Nicht alle parasitären Erkrankungen des Gastrointestinaltraktes sind importiert, sondern sie können auch direkt durch engen Tierkontakt vom Tier auf den Menschen übertragen werden. Die wichtigsten parasitären Erkrankungen des Gastrointestinaltraktes und der Leber werden im Folgenden vorgestellt.

Unterschiedliche Lebenszyklen. Im Gastrointestinaltrakt und im Gallengangsystem nisten sich Protozoen (Einzeller), Fadenwürmer (Nematoden), Bandwürmer (Cestoden) und Saugwürmer (Trematoden) ein. Bandwürmer und Saugwürmer gehören zu den Plattwürmern. Die Fortpflanzung der Bandwürmer ist zweigeschlechtlich; sie produzieren durch gegenseitige Befruchtung zahllose Nachkommen. Es kommt aber auch häufig zu einer Selbstbefruchtung, bei der

Samenzellen aus Proglottiden des vorderen Körperabschnittes die Eizellen in den Eierstöcken der Proglottiden des hinteren Körperabschnittes befruchten. Nachdem die befruchteten Eier in den Darm des Wirtes gelangen, werden sie in den Faeces nach außen befördert. Hier verbleiben sie, bis sie von einem geeigneten Zwischenwirt aufgenommen werden. Aus den Eiern schlüpfen die Larven der Bandwürmer [1 -3].

Die Saugwürmer sind durchgehend Endoparasiten mit komplexen Lebenszyklen; sie gehören zu einer Klasse von parasitär lebenden Plattwürmern. Die als Adernegel bekannten Saugwürmer befallen das Blut von Menschen und verursachen das in tropischen Klimazonen verbreitete Bild der Schistosomiasis bzw. Bilharziose $[3,4]$.

Epidemiologie und Nachweis. Wie bereits erwähnt, sind parasitäre Erkrankungen generell viel häufiger in tropischen und subtropischen Ländern zu finden und weniger in Europa und den industrialisierten Ländern. Die verstärkte Reisetätigkeit und die Immigrationsbewegungen haben aber dazu geführt, dass auch bei uns vermehrt parasitäre Krankheiten auftreten. Die Häufigkeit von parasitären Erkrankungen ist bei uns unklar, da es keine genauen Register zu den verschiedenen Krankheiten gibt und für die meisten Erreger keine Meldepflicht besteht [2]. 
Die Anzahl der nicht oder erst verzögert diagnostizierten Fälle ist relativ hoch, weil nicht daran gedacht wird. Der Verdacht muss sich aus der Anamnese ergeben: Aufenthalt in den Tropen oder Subtropen, chronisch rezidivierende Stuhlunregelmäßigkeiten oder eine unerklärte Eosinophilie sind Hinweise für eine Parasitose. Die Diagnose ist in der Regel relativ einfach: In den meisten Fällen genügt es, 3 Stuhlproben in einer SAF(sodium acetate acetic acid formalin) Lösung aufbewahrt zu analysieren. Der Stuhl sollte aber untersucht werden, bevor Medikamente (Antibiotika, Medikamente gegen Parasiten, Wismut etc.) verabreicht werden, weil sonst falsch negative Testergebnisse erzeugt werden können $[9,10]$.

Übertragung. Parasiten gelangen über unsauberes Trinkwasser oder kontaminierte Lebensmittel in den Körper oder werden direkt fäkal-oral übertragen. In Tab. 1 sind wichtige Risiken und entsprechende Erreger zusammengestellt. Bei Immigranten aus Entwicklungsländern können Parasiten in bis zu 60\% nachgewiesen werden, wobei Asylsuchende aus SubsaharaAfrika und aus Südostasien am stärksten betroffen sind.

Die Parasiten gelangen vor allem über kontaminiertes Wasser oder Nahrungsmittel in den Gastrointestinaltrakt, doch kommen auch Tier-zuMensch- oder Mensch-zu-Mensch-Übertragungen vor, vor allem bei Giardia lamblia, Oxyuren oder

\section{Tabelle 1}

Risiken durch unsauberes Wasser oder kontaminierte Nahrungsmittel (modifiziert nach [10]).

\begin{tabular}{|ll|}
\hline Risikofaktoren & Parasiten \\
\hline Unsauberes Wasser & Giardia lamblia, Cryptosporidia, Toxoplasmose etc. \\
\hline Süßwasserkontakt (Tropen) & Schistosomiasis \\
\hline $\begin{array}{l}\text { Rohe Früchte, Gemüse, } \\
\text { Salat }\end{array}$ & $\begin{array}{l}\text { Giardia lamblia, Cryptosporidia, Ascaris, Trichuris, } \\
\text { Taenia }\end{array}$ \\
\hline Fleisch & Taenia, Trichinella \\
\hline Süßwasserfisch & Fischbandwurm, Darm- und Leberegel \\
\hline Salzwasserfisch & Fischbandwurm, Anisakis \\
\hline Schnecken & kleine Trematoden \\
\hline Flusskrebse & Lungenegel \\
\hline Wasserpflanzen
\end{tabular}

Kryptosporidien. Auch eine sexuelle Übertragung ist möglich, insbesondere durch anale Praktiken.

Wann muss man daran denken? Die Risikoanamnese (Herkunft, Auslandsaufenthalt, Ernährung, Trinkwasser etc.) gibt wichtige Informationen. Aufgrund der geografischen Ausbreitung können bestimmte Parasitosen schon anhand der Anamnese ausgeschlossen werden. Klinisch sind unspezifische gastrointestinale Symptome im Vordergrund, oft verbunden mit Stuhlunregelmäßigkeiten (s. „Hinweise auf eine Parasitose“) $[8,10]$.

\section{Hinweise auf eine Parasitose}

- Anamnese: vermehrte Stuhlfrequenz, unspezifische Symptome wie Übelkeit, Erbrechen, unspezifische Bauchschmerzen, Reiseanamnese, Aufenthalt in tropischen und subtropischen Ländern

- Laborchemisch: Eosinophilie, unerklärte Anämie

- Alarmsymptome: blutige Diarrhö, starkes Erbrechen, Fieber, akutes Abdomen

- Abklärungsbedürftig: chronische Diarrhö, unerklärter Eisenmangel

\section{Protozoen}

\section{Giardiose}

Epidemiologie und Übertragung. Die Giardiose wird durch einen weltweit verbreiteten Parasiten Giardia lamblia oder Lamblia intestinalis verursacht, der vor allem den oberen Dünndarm des Menschen besiedelt. Die Inzidenz ist bei Kindern höher als bei Erwachsenen. Ungenügende sanitäre Einrichtungen und Hygiene fördern die Infektionsrate. Epidemien können vorkommen. Die Übertragung erfolgt fäkal-oral, wobei kontaminiertes Trinkwasser und Nahrungsmittel die wichtigsten Infektionsquellen darstellen. Das Infektionsrisiko wird durch die Lebens- und Trinkwasserhygiene und die Abwasser- und Fäkalienbeseitigung bestimmt. Nicht behandelte Zystenträger bilden ein Infektionsrisiko (Immigranten und Reisende aus Endemiegebieten). Lamblienzysten sind in der Regel resistent gegen übliche Wasseraufbereitungsmaßnahmen. Die Übertragung der Lamblienzysten erfolgt durch Zysten in kontaminiertem Trinkwasser oder kontaminierter Nahrung. Kinder und Immunsupprimierte sind in der Regel stärker betroffen. 

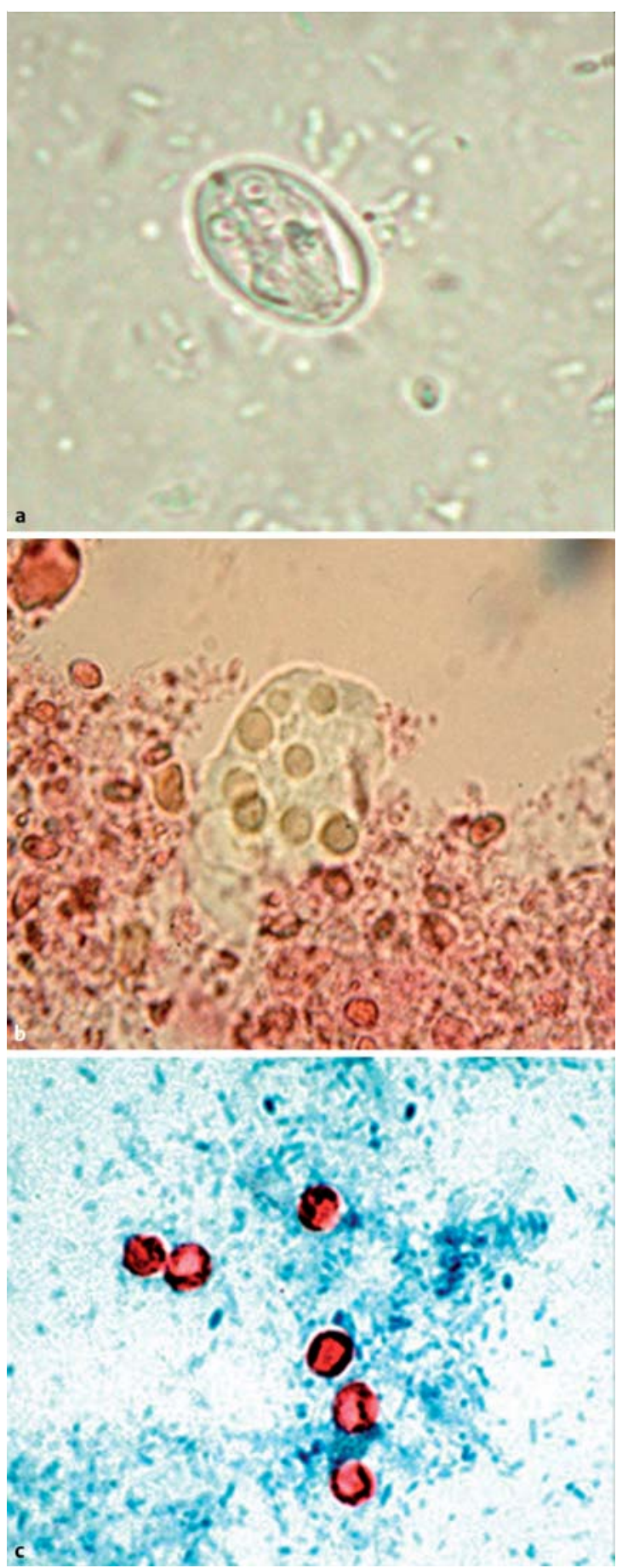

Abb. 1 Intestinale Protozoen. a Giardia-Zyste (ungefärbt im Duodenalsekret). b Erythrozytophager Trophozoit von Entamoeba histolytica. c Cryptosporidium parvum (modifizierte Ziehl-Neelson-Färbung) (aus Riemann, Fischbach, Galle, Mössner: Gastroenterologie in Klinik und Praxis. Stuttgart: Thieme).

Pathogenese. Nach der Aufnahme von Zysten (Abb. 1 a) entwickeln sich diese zu Trophozoiten und vermehren sich im Duodenum und Dünndarm (Abb.2). Die Inkubationszeit beträgt in der Regel 1-2 Wochen, kann aber auch sehr viel länger sein. Die Pathogenese ist multifaktoriell und wird durch eine verminderte Motilität, durch IgA- und IgG-Mangel und durch mukosale Defekte gefördert. Die Mehrheit der Giardiosen verläuft asymptomtisch.

Klinik. Die Klinik der Giardiose ist sehr variabel und reicht, wie erwähnt, vom symptomlosen Träger (häufig in endemischen Gebieten) bis zur schweren Durchfallerkrankung mit Malabsorption. Die wesentlichen Symptome sind in Tab. 2 zusammengefasst. Flüssige bis wässrige, übelriechende Stuhlentleerungen (bis 10-mal pro Tag) können vorkommen. Gewichtsverlust, Nausea, Aufstoßen und Bauchkrämpfe sind häufige Symptome, manchmal assoziiert mit Müdigkeit und Leistungsverminderung. Aufstoßen mit einem Geruch nach faulen Eiern ist beschrieben worden. Giardia lamblia werden selten auch in den Gallenwegen und in der Lunge gefunden.

Etwa die Hälfte der mit Giardia lamblia infizierten Personen entwickelt gastrointestinale Symptome.

Labordiagnostik. Die Diagnose wird durch den Nachweis von Zysten oder Trophozoiten im Stuhl gestellt, wobei ein spezifischer ELISA-Test zur Verfügung steht, der den Nachweis eines Giardia-Antigens im Stuhl erlaubt (Sensitivität des Tests $>90 \%$, Spezifität $98 \%$ ). In der Regel werden 3 Stuhlproben untersucht. Damit ist nur noch selten ein histologischer Nachweis aus Dünndarmbiopsien notwendig. Giardia lamblia kann auch im Duodenalsaft oder in der Galle nachgewiesen werden, doch ist dieser Nachweis in der Klinik nicht notwendig.

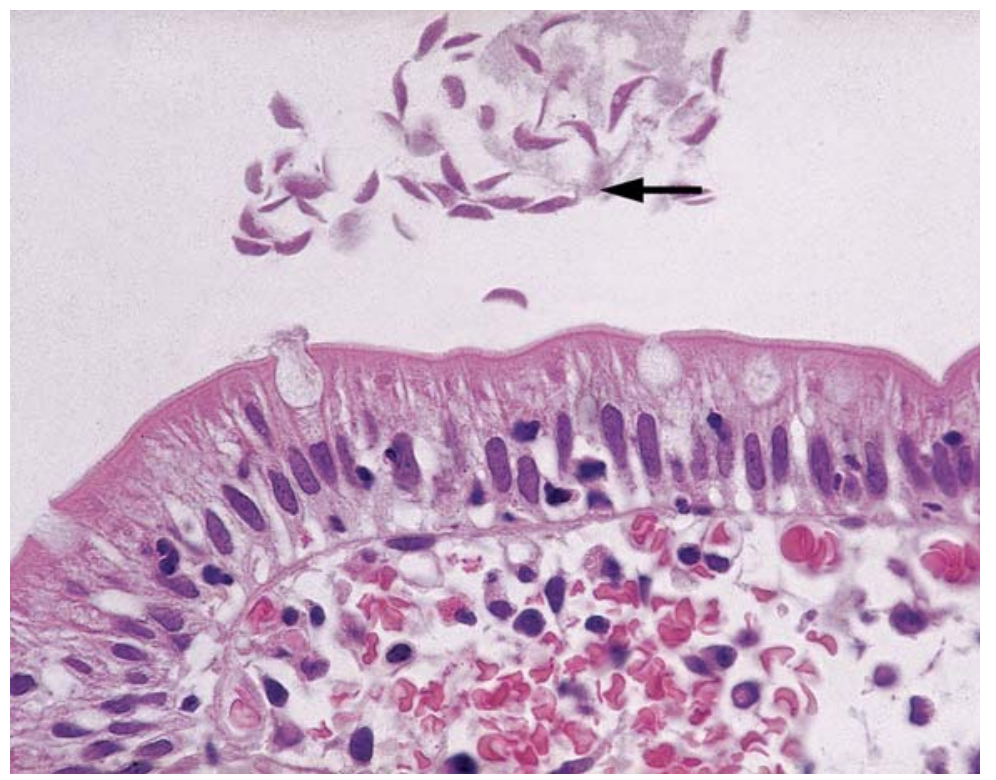

Abb.2 Giardiasis-Enteritis. Auf der Zottenoberfläche sind zahlreiche sichelförmige Trophozoiten erkennbar. 


\begin{tabular}{|l|}
\hline Tabelle 2 \\
\hline Typische Symptome bei Giardiose. \\
\hline - Durchfall (dünn bis wässrig) \\
\hline - Abdominalschmerzen \\
\hline - Übelkeit und Erbrechen (im Akutstadium) \\
\hline - Malabsorptionssymptome \\
\hline
\end{tabular}

Serologische Untersuchungen sind aufgrund des einfachen Stuhltests nicht notwendig (und auch nicht sinnvoll). Eine Bluteosinophilie tritt nicht auf.

Therapie. Sowohl symptomatische als auch exponierte asymptomatische Personen sollten behandelt werden.

- Asymptomatische Zystenträger: Es sollten nur Personen, die in der Lebensmittelbranche tätig sind, behandelt werden. Die Behandlung asymptomatischer Träger ist sonst äußerst umstritten. Kontrollierte Daten fehlen.

- Symptomatische Patienten sollten mit oralen 5-Nitroimidazol-Präparaten über 5-7 Tage hinweg behandelt werden (Metronidazol $3 \times 500 \mathrm{mg} /$ Tag für 7 Tage oder Tinidazol $2 \mathrm{~g}$ oral als Einzeldosis oder Ornidazol $2 \times 500 \mathrm{mg} /$ Tag für 5 Tage).

Die Wirksamkeit von Tinidazol beträgt 90-98\%; Resistenzen sind sehr selten. Bei immunkompromittierten Patienten sollte die Therapie 6-8 Wochen verabreicht

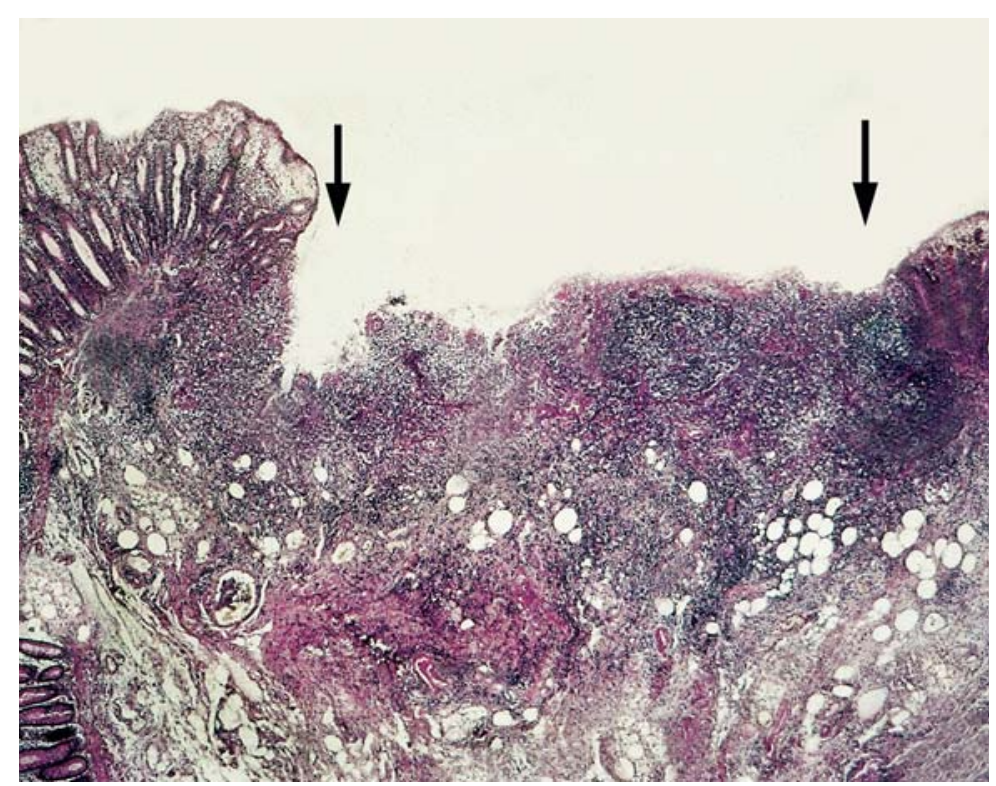

Abb. 3 Amöbenkolitis. Die Amöben haben eine umschriebene Nekrose der Mukosa in Form eines Ulkus (Pfeile) verursacht. werden. Nach der Behandlung sollte der Therapieerfolg mittels Stuhltest überprüft werden $[5,10]$.

Die Giardiose kann durch Antigennachweis im Stuhl diagnostiziert werden. Symptomatische Patienten und asymptomatische Zystenträger, die in der Lebensmittelbranche beschäftigt sind, sollten mit

5-Nitroimidazol-Präparaten behandelt werden.

\section{Amöbiasis (E. histolytica und E. dispar)}

Epidemiologie. Es gibt zwei morphologisch sehr ähnliche Spezies, die früher generell als E. histolytica bezeichnet wurden. Heute wird nur die pathogene Spezies E. histolytica genannt, die nichtpathogene Form E. dispar. Beide Formen werden weltweit häufig nachgewiesen; es wurde geschätzt, dass 10\% der Weltbevölkerung mit E. histolytica infiziert sind. Die höchste Inzidenz (bis zu 80\%) findet sich in den Tropen und Subtropen, insbesondere in Zentral- und Südamerika, in Indien und im tropischen Asien sowie in Afrika. Wie erwähnt, sind nicht alle Amöben pathogen und therapiebedürftig. Klinisch relevant und im Vordergrund des Interesses ist die invasive Form E. histolytica. Auch wenn sie im Allgemeinen als einzige pathogene Spezies gilt, gibt es Case Reports von anderen Amöbenspezies, die mit einer gastrointestinalen Erkrankung assoziiert worden sind: E. dispar, E. hartmanni, E. coli und andere.

Übertragung. Die Übertragung erfolgt fäkal-oral durch infektiöse Zysten, wobei kontaminiertes Trinkwasser und Nahrungsmittel die wichtigste Infektionsquelle darstellen. Das Infektionsrisiko wird durch die Lebensund Trinkwasserhygiene und die Abwasser- und Fäkalienbeseitigung bestimmt. In Europa sind vor allem Immigranten und Reisende betroffen.

Pathogenese. Die Inkubationszeit beträgt wenige Tage, kann aber auch wesentlich länger (Monate) dauern. Nach ihrer Ausscheidung können die Zysten außerhalb des Körpers mehrere Wochen überleben, die Trophozoiten (Abb. 1b) hingegen überleben nicht außerhalb des Wirtes. Die Amöben produzieren Toxine, die im Wirt zu Destruktion der Mukosa führen mit unspezifischer Entzündungsreaktion sowie Ulzerationen (Abb.3). Die Parasiten können so in den Körper eindringen, wo sie über das Portalsystem in die Leber gelangen oder in andere Organe. Viele Infizierte sind asymptomatische Träger, die den Parasiten innerhalb von Monaten wieder spontan eliminieren. 
Klinik. Etwa jeder zehnte Infizierte wird symptomatisch. Die Klinik ist variabel und reicht vom asymptomatischen Zystenausscheider über milden Durchfall bis zu blutiger Dysenterie und toxischem Megakolon. Das klinische Bild wird durch die Ausdehnung der Infektion im Gastrointestinaltrakt bestimmt. Bei Patienten, die eine Amöbenkolitis entwickeln, treten die typischen Symptome auf (Tab.3), wobei eine intermittierende, blutige Diarrhö verbunden mit Bauchkrämpfen und Tenesmen im Vordergrund steht. Dieses Krankheitsbild ist klinisch von einer Colitis ulcerosa nur schwer zu unterscheiden. Bei schwerem Verlauf kann es (wie bei der Colitis ulcerosa) zu einer Perforation kommen, ein toxisches Megakolon entwickelt sich in weniger als $1 \%$ der Patienten mit Amöbenkolitis. Die wichtigste Komplikation ist der Amöbenabszess (s. „Leberabszess bei Amöbiasis“).

\section{Tabelle 3}

\section{Typische Symptome bei Patienten mit Amöbenkolitis.}

- Abdominalschmerzen

- Intermittierende blutige Durchfälle

- Allgemeines Krankheitsgefühl (Malaise)

- Anorexie

Die Amöbenkolitis ist gekennzeichnet durch intermittierende blutige Durchfälle und abdominelle Schmerzen je nach Ausdehnung der Infektion. Die wichtigste extraintestinale Manifestation der Amöbiasis ist der Leberabszess.

Labordiagnostik. Die mikroskopische Unterscheidung von Entamoeba histolytica und Entamoeba dispar ist nicht möglich; hingegen können die beiden Formen durch den Nachweis von spezifischen Antigenen differenziert werden. Die Diagnosestellung erfolgt durch Amöben- bzw. Zystennachweis im Stuhl, wofür ein spezifischer ELISA-Test zur Verfügung steht, der den Nachweis eines spezifischen Entamoeba-hystolyticaAntigens im Stuhl erlaubt (Sensitivität des Testes 85 $90 \%$, Spezifität $>90 \%$ ). Bei schwerer Kolitis ist eine rasche Diagnose auch durch Endoskopie und Biopsieentnahme möglich. Neu sind PCR-Methoden, die den Nachweis spezifischer Amöbensequenzen im Stuhl ermöglichen; die PCR-Methode ist äußerst empfindlich, aber wesentlich teurer als ein ELISA-Test.

\section{Komplikationen}

Leberabszess bei Amöbiasis Organe ist möglich (Abb. 4). Am häufigsten ist eine Dissemination in die Leber (in etwa $1 \%$ aller Fälle), wobei Männer von dieser Komplikation öfter betroffen sind als Frauen. Leberabszesse sind in der Regel solitär und in der rechten Leberhälfte lokalisiert. Sie treten während der akuten enteritischen Phase auf, können aber auch Jahre nach der Primärinfektion noch vorkommen. Die Klinik des Leberabszesses ist charakterisiert durch Fieber, Schüttelfrost und allgemeines Unwohlsein, eventuell verbunden mit Nausea und Erbrechen. Schmerzen im rechten Oberbauch
Eine Dissemination in fast alle sind möglich, wobei die Schmerzen durch Husten oder Atmen verstärkt werden können.

Der Abszess wird sonografisch diagnostiziert, punktiert und drainiert. Typischerweise wird eine dicke, braune Flüssigkeit drainiert („Schokoladensauce“). Die Diagnose „Amöbenabszess“ kann allerdings sonografisch nur vermutet werden und in der Regel auch aus dem Punktat nicht gestellt werden (die Parasiten befinden sich in der Wand des Abszesses und nicht in der Flüssigkeit). Die Leukozyten und das C-reaktive Protein sind erhöht, eine Bluteosinophilie ist nicht vorhanden.

\section{Amöbeninfektion - Manifestation}

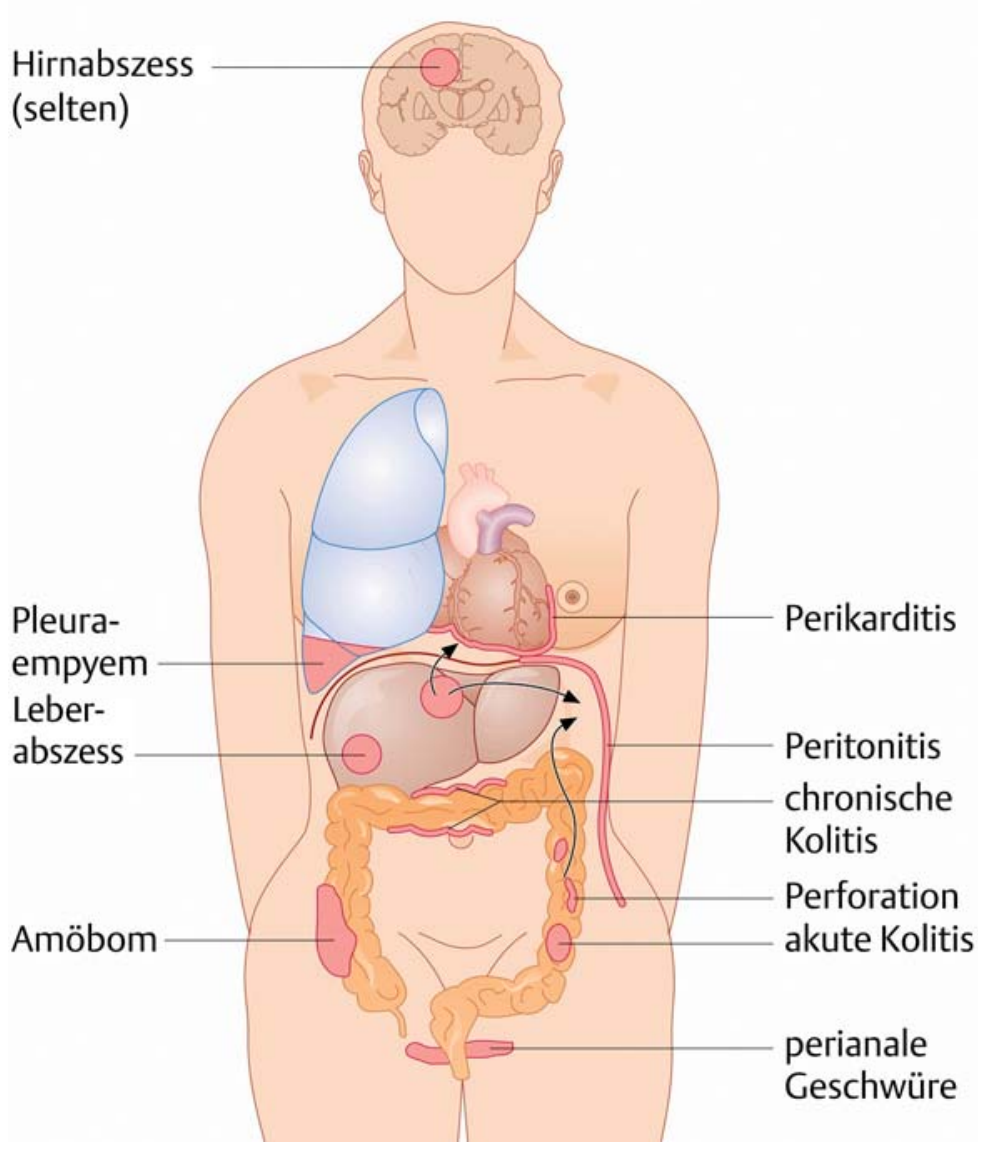

Abb.4 Intestinale und extraintestinale Manifestationen der Amöbiasis. 
Serologische Untersuchungen sind bei intestinaler Krankheit wenig hilfreich, weil die Sensitivität der Tests ungenügend ist. Bei extraintestinaler Krankheit (z.B. Leberabszess) sind die serologischen Tests aber sehr empfindlich und verlässlich (hohe Sensitivität und Spezifität). Ein Problem der serologischen Tests ist jedoch, dass sie noch jahrelang positiv bleiben können; damit kann nicht zwischen akutem Infekt und ausgeheilter Erkrankung unterschieden werden. Dies ist in unseren Breitengraden vor allem bei Immigranten mit entsprechenden Symptomen ein Problem, ist doch bis ein Drittel dieser Personen serologisch gegen Amöben positiv. Bei dieser Patientengruppe sollte deshalb primär ein Stuhltest durchgeführt werden.

Die Diagnose einer Amöbenkolitis wird mittels Antigennachweis im Stuhl gestellt, während serologische Untersuchungen bei extraintestinaler Krankheit sehr empfindlich und verlässlich sind.

Differenzialdiagnose. Die Leitsymptome der Amöbenkolitis definieren die differenzialdiagnostischen Überlegungen: Andere infektiöse und nicht infektiöse inflammatorische Ursachen müssen ausgeschlossen werden. Differenzialdiagnostisch muss deshalb auch an einen Morbus Crohn oder eine Colitis ulcerosa gedacht werden. Beide Krankheiten werden oft mit Steroiden behandelt, wofür eine akute Amöbenerkrankung eine klare Kontraindikation darstellt, da eine Behandlung mit Steroiden eine Dissemination der Infektion fördern und zum Tode führen kann.

Therapie. Die akute, invasive Amöbiasis wird durch Metronidazol behandelt $(3 \times 750 \mathrm{mg}$ per os für $7-10$ Tage; alternativ Tinidazol per os $2 \mathrm{~g}$ /Tag für 5-10 Tage). Metronidazol ist vor allem systemisch wirksam, aber weniger im Darmlumen. Es sollte deshalb mit einem oralen Kontaktamöbizid kombiniert werden: Paromomycin $3 \times 500 \mathrm{mg} /$ Tag für 7-10 Tage oder Diloxanidfuroat $3 \times 500 \mathrm{mg} /$ Tag für 10 Tage. Asymptomatische Amöbenträger werden mit luminalen Kontaktamöbiziden therapiert $[5,10]$.

Die medikamentöse Behandlung der Leberabszesse ist ausreichend; die Punktion und Entleerung von Abszessen führt jedoch zu einer raschen Abheilung und kann Komplikationen verhindern.

\section{Blastozystose}

Epidemiologie und Übertragung. Der Erreger Blastocystis hominis kommt weltweit vor und vermehrt sich sowohl sexuell als auch asexuell. In den Subtropen und Tropen tritt er gehäuft auf. Die Übertragung erfolgt durch infektiöse Zysten in kontaminiertem Trinkwasser oder kontaminierter Nahrung. Die Pathogenität des Erregers ist unklar.

Klinik. Etwa ein Drittel aller mit Blastocystis hominis infizierter Personen ist völlig asymptomatisch. Die anderen zwei Drittel zeigen eine wechselnde Klinik. Durchfall, Nausea, Erbrechen oder unangenehme Blähungen, verbunden mit Abdominalschmerzen, sind beschrieben. Die Krankheit ist in der Regel selbstlimitierend; chronische Verläufe sind aber bekannt.

Labordiagnostik. Die Diagnose wird durch den Nachweis von Blastocystis hominis in frischem Stuhl gestellt. Die Menge der Erreger sollte vom Labor mitgeteilt werden, da die klinische Symptomatik mit der Erregermenge korreliert.

Therapie. Metronidazol $3 \times 750 \mathrm{mg} /$ Tag per os während 10 Tagen oder Ornidazol $2 \mathrm{~g}$ als Einzeldosis gelten als Therapie der Wahl.

\section{Trypanosomiasis (Chagas-Erkrankung)}

Epidemiologie und Übertragung. Der Erreger Trypanosoma cruzi ist ein großes Gesundheitsproblem: Vor allem in Süd- und Zentralamerika sind mehrere Millionen Menschen von der Infektion betroffen; in gewissen Gegenden sind 10\% aller Todesfälle durch die ChagasKrankheit verursacht. Die Übertagung der Parasiten erfolgt durch Insektenstiche.

Pathogenese. Der Parasit wird durch Kratzen in die Haut gerieben, wo er sich in Histiozyten und anderen Zellen einnistet und vermehrt. Nach ein paar Tagen platzen die infizierten Zellen, wobei Trypomastigoten in die Blutbahn gelangen. Dadurch können alle Organe des Körpers befallen werden; bevorzugt vermehrt sich der Parasit jedoch im retikuloendothelialen System, in Muskelzellen und in der Glia.

Klinik. An der Stichstelle entwickelt sich eine lokale Entzündung mit subkutanen Knoten (Chagom). Lokale Lymphknoten können geschwollen sein. Vor allem bei Kindern können schwere Infektionen vorkommen mit 
erythematösem Exanthem, hohem Fieber, Hepatosplenomegalie und Myokarditis.

Eine chronische Erkrankung erfolgt in der Regel Jahre nach der Primärinfektion: Autoimmunantikörper gegen Myokardzellen, Muskelzellen und Nervenzellen verursachen irreversible Defekte. Als Folge können sich eine Kardiomyopathie und Rhythmusstörungen entwickeln, die in einer Herzinsuffizienz enden. Eine Denervierung der myenterischen Plexus kann zu Achalasie, Megakolon mit Obstipation und anderen Darmstörungen führen. Infizierte Mütter können den Parasiten auf den Fetus übertragen.

Die chronische Trypanosomiasis führt durch Autoantikörper gegen Myokardzellen, Muskelzellen und Nervenzellen zu irreversiblen Defekten.

Labordiagnostik. Die Diagnose wird durch den Nachweis im Blutausstrich erbracht oder histologisch im Knochenmark oder in Lymphknoten durch eine Giemsafärbung. Neuerdings werden PCR-Methoden verwendet, um den Erreger nachzuweisen. Der Antikörpernachweis ist unzuverlässig, da eine aktive Erkrankung nicht von einer durchgemachten Krankheit unterschieden werden kann.

Therapie. Nifurtimox $2 \mathrm{mg} / \mathrm{kg}$ KG 4-mal täglich während 4 Monaten gilt als erfolgreiche Therapie, um die Menge der Parasiten, die Symptome und in Einzelfällen die Mortalität zu senken $[5,10]$.

\section{Kryptosporidiose}

Epidemiologie und Übertragung. Cryptosporidium parvum (Abb. 1 c) gilt als einzige humanpathogene Spezies in der Gruppe der Kryptosporidien. C. parvum ist eine seltene Ursache für eine akute infektiöse Diarrhö bei immunkompetenten Personen. Bei immunkompromittierten Patienten (insbesondere AIDS) kann es aber zu einem chronischen Infekt mit dem Hauptsymptom Durchfall kommen. Die Übertragung erfolgt fäkal-oral durch infizierte Patienten oder kontaminiertes Trinkwasser und Nahrungsmittel. C. parvum ist in Schwimmbäder und anderem oberflächlichem Wasser nachweisbar; der Erreger ist relativ resistent gegen Desinfektionsmittel.

Klinik. Die Inkubationszeit beträgt etwa eine Woche. Akut wässrige Durchfälle, verbunden mit Bauchkrämpfen, sind die Hauptsymptome. Der klinische Verlauf ist sehr variabel und kann sehr milde sein bis hin zu heftigen Durchfällen mit ausgeprägtem Flüssigkeitsund Elektrolytverlust. Die schweren Verläufe werden vorwiegend bei immunkompromittierten Patienten oder bei Kindern beobachtet. Bei diesen Patienten kann die Krankheit auch das biliäre System befallen mit Entwicklung einer akuten Cholezystitis und einer sklerosierenden Cholangitis.

Labordiagnostik. Die Diagnose wird im Stuhl gestellt, wobei ein spezifischer ELISA-Test zur Verfügung steht, der den Nachweis eines Cryptosporidium-Antigens im Stuhl erlaubt (Sensitivität des Testes $>90 \%$, Spezifität $98 \%$ ). Alternativ ist ein Nachweis mit PCR möglich (teurer als ELISA).

Therapie. Eine zuverlässige Therapie gegen Cryptosporidium parvum existiert nicht. Eine orale Behandlung mit Paromomycin $3 \times 500 \mathrm{mg} /$ Tag für $7-10$ Tage wird empfohlen; bei Immunsuppression oder HIV ist eine längere Therapiedauer notwendig. Bei immunkompromittierten Patienten ist vor allem eine Rekonstitution der Immunkompetenz die beste Strategie (z. B. antiretrovirale Kombinationsbehandlung bei HIV) $[5,10]$.

Cryptosporidium parvum kann vor allem bei immunkompromittierten Patienten zu heftigen Durchfällen mit ausgeprägtem Flüssigkeits- und Elektrolytverlust führen.

\section{Andere intestinale pathogene Protozoonosen}

Isospora belli, Mikrosporidien. Mikrosporidien sind eine seltene Ursache für eine akute infektiöse Diarrhö bei immunkompetenten Personen. Bei immunkompromittierten Patienten kann es aber zu einem chronischen Infekt kommen mit dem Hauptsymptom Durchfall. Die Übertragung erfolgt fäkal-oral durch infizierte Patienten oder kontaminiertes Trinkwasser und Nahrungsmittel.

Klinik. Die Inkubationszeit beträgt etwa eine Woche. Wässrige Durchfälle, verbunden mit Bauchkrämpfen, sind die Hauptsymptome. Der klinische Verlauf ist sehr variabel und kann sehr milde sein bis zu heftigen Durchfällen verbunden mit Übelkeit und Gewichtsverlust. Schwere Verläufe werden insbesondere bei immunkompromittierten Patienten beobachtet. Hier kann die Krankheit auch das biliäre System befallen und zur Entwicklung einer akuten Cholezystitis und einer sklerosierenden Cholangitis führen. 

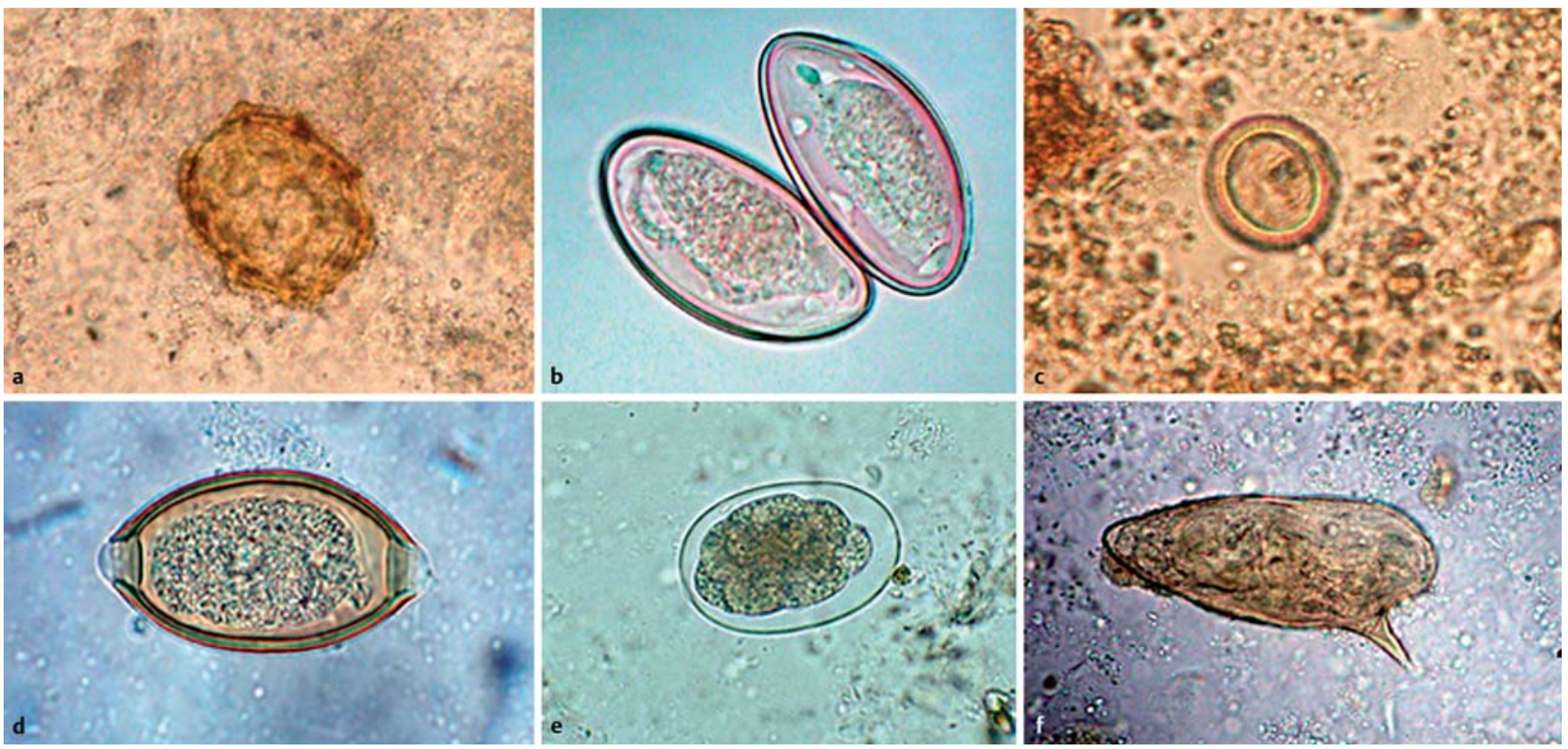

Abb. 5 Helmintheneier. a Ascaris lumbricoides. b Enterobius vermicularis. c Taenia spec. d Trichuris trichiura. e Hakenwurm. f Schistosoma mansoni (aus Riemann, Fischbach, Galle, Mössner: Gastroenterologie in Klinik und Praxis. Stuttgart: Thieme).

Labordiagnostik. Die Diagnose wird im Stuhl gestellt, wobei ein spezifischer ELISA-Test sowie ein PCR-Nachweis zur Verfügung stehen. Selten gelingt ein histologischer Nachweis aus Dünndarmbiopsien.

Therapie. Die Therapie von Mikrosporidien erfolgt mittels Albendazol $2 \times 400 \mathrm{mg} /$ Tag per os für 3 Wochen; bei HIV-Positivität muss die Therapie länger verabreicht werden.

Die Therapie von Isospora belli erfolgt mittels Trimethoprim-Sulfamethoxazol 160/800 mg 2-mal täglich per os für 7 Tage; alternativ Ciprofloxacin $2 \times 500 \mathrm{mg} /$ Tag per os für 7 Tage $[5,10]$.

Abb. 6 Spulwurm.

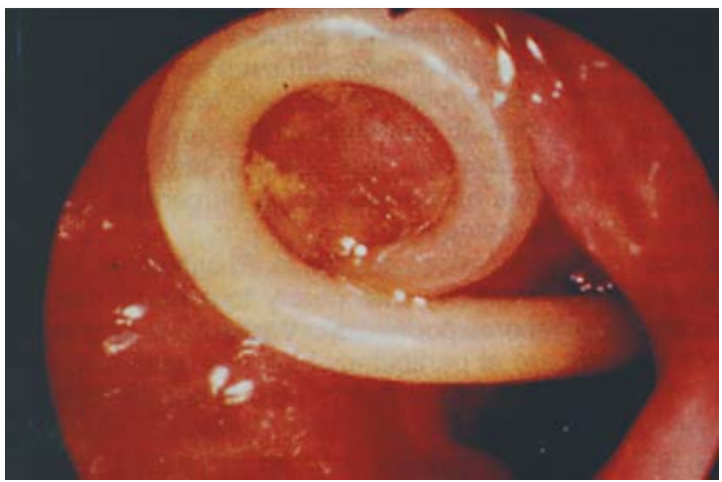

\section{Helminthen}

\section{Fadenwürmer (Nematoden)}

\section{- Askariasis}

Epidemiologie und Übertragung. Der Erreger (Ascaris lumbricoides oder Spulwurm) kommt weltweit vor, wobei die Inzidenz in warmen, feuchten Gegenden (Tropen, Subtropen) deutlich höher ist. Das Infektionsrisiko wird durch die Lebensmittel- und Trinkwasserhygiene und die Abwasser- und Fäkalienbeseitigung bestimmt. In Europa sind vor allem Immigranten und Reisende aus Endemiegebieten betroffen. Die Übertragung erfolgt durch Schlucken von Eiern (Abb.5a) in kontaminiertem Trinkwasser oder kontaminierter Nahrung.

Pathogenese. Im Duodenum entstehen Larven aus den geschluckten Eiern, welche die Wand penetrieren und ins portalvenöse System gelangen. Die Larven werden über den Blutweg in die Lungen transportiert, wo sie eine Pneumonitis verursachen. Sie migrieren anschließend ins Bronchialsystem, gelangen in den Rachen und werden wieder geschluckt. Im Dünndarm reifen sie zu erwachsenen Würmern (Abb.6).

Klinik. Asymptomatische Verläufe sind nicht ungewöhnlich. Die Klinik wird bestimmt durch die Menge der Parasiten; chronische Darmbeschwerden mit Malabsorption und Gewichtsverlust und Anämie sind 
möglich. Diese Verläufe werden vor allem in Entwicklungsländern beobachtet, sind aber auch bei Migranten mit chronischen gastrointestinalen Symptomen vorhanden. Bei uns sind gastrointestinale Symptome sehr selten. 1-2 Wochen nach Aufnahme entsteht in der Regel durch lokale Entzündung und Hypersensitivität eine Pneumonitis mit Fieber, Husten, Dyspnoe, Bluteosinophilie sowie Infiltraten im Thoraxröntgenbild (Löffler-Syndrom). Die Überlebenszeit der Würmer im Darm beträgt 6 - 18 Monate. Die Diagnose einer Askariasis ist oft eine Zufallsdiagnose bei Routinestuhluntersuchungen [6].

Labordiagnostik. Ein weiblicher Wurm produziert mehrere 100000 Eier pro Tag; die mikroskopische Untersuchung einer Stuhlprobe genügt deshalb, um den Wurm nachzuweisen.

Therapie. Die Therapie der Wahl sind Benzoimidazole; diese haben eine hohe Wirksamkeit (nahe 100\%) bei einer sehr guten Verträglichkeit. Therapieoptionen sind: Albendazol $400 \mathrm{mg}$, einmalig; Mebendazol $2 \times 100 \mathrm{mg} /$ Tag über 3 Tage $[5,10]$.

Da gastrointestinale Symptome im Rahmen einer Askariasis bei uns eher selten sind, erfolgt die Diagnosestellung meist zufällig bei einer Routinestuhluntersuchung.

\section{- Trichuriasis}

Epidemiologie und Übertragung. Der Erreger (Trichuris trichiura oder Peitschenwurm) kommt weltweit vor, bei uns sind vorwiegend Migranten aus den Tropen und Subtropen betroffen. Die Übertragung erfolgt fäkaloral, oft durch Schlucken der Eier (Abb.5d) mit dem Essen, speziell beim Verzehr von rohem Gemüse. Die Eier des Wurmes gelangen ins terminale Ileum und das Kolon, wo sie den Darm besiedeln. Der Peitschenwurm bohrt sich mit seinem Kopf in die Wand von terminalem Ileum und Zäkum, was zu blutigem Durchfall und Anämie führen kann.

Klinik. Der Verlauf ist meist symptomlos. Unspezifische Abdominalbeschwerden wie Nausea, Erbrechen, Meteorismus und Durchfall können vorkommen. Das Auftreten einer Anämie und Eosinophilie ist nicht ungewöhnlich, wie oben erwähnt. Vor allem bei Kindern sind Symptome vorhanden: Durchfall, Anämie und Wachstumsstörungen stehen dabei im Vordergrund. Die Diagnose einer Trichuriasis ist aber in der Regel eine Zufallsdiagnose bei Routinestuhluntersuchungen.
Labordiagnostik. Die mikroskopische Untersuchung einer Stuhlprobe genügt, um die Wurmeier nachzuweisen. Es besteht oft eine Bluteosinophilie.

Therapie. Mebendazol $1 \times 500 \mathrm{mg} /$ Tag per os während 3 Tagen; alternativ: Albendazol $400 \mathrm{mg}$ als Einmaldosis per os (bei schweren Infektionen $400 \mathrm{mg}$ per os während 3 Tagen) [10].

Symptome einer Trichuriasis treten vor allem bei Kindern auf: Durchfall, Anämie und Wachstumsstörungen sind die häufigsten.

\section{Oxyuriasis}

Epidemiologie und Übertragung. Der Erreger (Enterobius vermicularis, auch Oxyuris genannt, oder Madenwurm) kommt weltweit vor; überwiegend sind Kinder betroffen, doch können auch ganze Familien betroffen sein. Die Übertragung erfolgt fäkal-oral, oft durch kontaminierte Nahrung oder Gegenstände, speziell auch durch fäkal-orale Autoinfektion (Händehygiene!). Die Eier (Abb.5b) des Wurmes gelangen ins Kolon, wo sie die Ileozäkalgegend besiedeln (Kolon, Appendix). Die weiblichen Würmer wandern nachts zum Anus und legen dort Eier an der perianalen Haut ab.

Klinik. Der Verlauf ist meist symptomlos; Symptome kommen vorwiegend bei Kindern in Form von perianalem Juckreiz vor, bei Mädchen auch als Pruritus vulvae oder eine Vulvovaginitis. Sehr selten sind eine Appendizitis oder eine Appetitlosigkeit mit Gewichtsverlust.

Labordiagnostik. Die mikroskopische Untersuchung der Eier, die durch einen perianalen Klebestreifen gewonnen werden (Scotch-Tape-Methode: Abklatsch von der perianalen Haut mit Hilfe eines Klebestreifens direkt morgens nach dem Aufstehen), ist diagnostisch. Eine Bluteosinophilie besteht nicht.

Therapie. Mebendazol, $300 \mathrm{mg}$ per os als Einmaldosis; alternativ: Albendazol $400 \mathrm{mg}$ als Einmaldosis per os. Wiederholung der Therapie nach 10-14 Tagen [10].

Bei Verdacht auf Oxyuriasis wird direkt morgens nach dem Aufstehen von der perianalen Haut mithilfe eines Klebestreifens ein Abklatsch gewonnen, mit dem der Nachweis der nachts perianal abgelegten Eier gelingt. 


\section{- Strongyloidiasis}

Epidemiologie und Übertragung. Der Erreger (Strongyloides stercoralis oder Zwergfadenwurm) kommt weltweit vor, wobei die Inzidenz in warmen, feuchten Gegenden (Tropen, Subtropen) markant höher ist. Bei uns sind vor allem Migranten aus Südostasien oder der Subsahara betroffen. Immunkompromittierte Patienten sind anfälliger für eine Strongyloides-Infektion; HIV und AIDS haben deshalb zu einer Zunahme der Erkrankungen geführt.

Nach dem Schlüpfen aus dem Ei entwickelt sich die Larve in der Erde entweder in einen freilebenden adulten Wurm oder in eine filariforme Larve, welche die menschliche Haut durchdringt und via Blutstrom in die Lunge gelangt. Eine Besonderheit des Zwergfadenwurmes ist seine Fähigkeit zur Autoinfektion. Dies bedeutet, dass die Larven des Wurms die Duodenalmukosa durchbrechen können und die chronische Infektion so ohne eine außerhalb des Wirtes stattfindende Entwicklung unterhalten können [7].

Pathogenese. Die Larven migrieren anschließend ins Bronchialsystem, gelangen in den Rachen und werden geschluckt. In der Mukosa des Dünndarms werden Eier abgelegt. Diese Form der Larven gelangt von der Mukosa ins Darmlumen und in den Stuhl, wo der Zyklus nach Ausscheidung von vorne beginnt.

Klinik. Die Strongyloidiasis kann asymptomatisch verlaufen, manifestiert sich aber in der Regel als chronische oder rezidivierende Infektion mit wiederholten Bauchschmerzen, Durchfall und Eosinophilie. Die wesentlichen Symptome sind in Tab. 4 zusammengefasst. Am Ort der Hautpenetration kann ein Erythem mit Papeln entstehen, die Haut juckt. 1 -2 Wochen nach dem Eindringen entsteht durch lokale Entzündung und Hypersensitivität eine Pneumonitis mit Fieber, Husten, Dyspnoe, Bluteosinophilie sowie Infiltraten im Thoraxröntgenbild (Löffler-Syndrom) wie beim

\section{Komplikationen}

Arthritiden und Dissemination bei Strongyloidiasis Falls die Diagnose über längere Zeit nicht gestellt wird, können auch reaktive Arthritiden auftreten. Die Überlebenszeit der Würmer im Menschen kann 30 Jahre dauern. Eine Dissemination ist vor allem bei immunkompromittierten Patienten beschrieben worden (Achtung: eine Steroidtherapie kann eine Dissemination fördern), wobei alle Organe des menschlichen Körpers befallen werden können, teilweise mit letalem Ausgang.

\section{Tabelle 4}

Typische Symptome bei Strongyloides-Infektion.

\begin{tabular}{|l|l|}
\hline Organe & Symptome \\
\hline Haut & juckende Exantheme \\
\hline Lunge & $\begin{array}{l}\text { Hypersensitivitätsreaktion, } \\
\text { Pneumonitis }\end{array}$ \\
\hline Gastrointestinaltrakt & $\begin{array}{l}\text { Bauchschmerzen (Krämpfe), } \\
\text { Durchfall, Erbrechen, Gewichts- } \\
\text { verlust }\end{array}$ \\
\hline
\end{tabular}

Askarisbefall. Gastrointestinale Symptome werden bestimmt durch die Menge der Parasiten: abdominale Schmerzen, vor allem im Epigastrium, Erbrechen, Durchfall (manchmal blutig) und Gewichtsverlust.

Labordiagnostik. Screening ist durch Serologien möglich. Die Diagnosestellung erfolgt durch Nachweis der Larven im Duodenalsaft oder im Stuhl. Eine Bluteosinophilie ist in der Regel vorhanden, in fortgeschrittenem Stadium können eine Eisenmangelanämie und eine Hypalbuminämie auftreten.

Therapie. Therapieoptionen sind: Ivermectin $200 \mathrm{mg} / \mathrm{kg} \mathrm{KG} /$ Tag während 3 Tagen; alternativ: Albendazol 2×400 mg/Tag während 7-10 Tagen [10].

Immunsupprimierte Patienten sind anfälliger für eine Strongyloidiasis. Die Intensität der gastrointestinalen Symptome hängt von der Parasitenmenge ab. Die Diagnose wird durch den Nachweis von Larven in Duodenalsaft oder Stuhl gestellt.

\section{Ankylostomiasis}

Epidemiologie und Übertragung. Der Erreger (Ancylostoma duodenale, auch Necator americanus oder Hakenwurm genannt) kommt vor allem in der Landbevölkerung in den Tropen und Subtropen vor. Die Übertragung erfolgt perkutan, meist über die Füße, indem die Larve die menschliche Haut durchbohrt und via Blutstrom in die Lunge gelangt.

Pathogenese. Die Larven migrieren anschließend ins Bronchialsystem, gelangen in den Rachen und werden geschluckt, woraufhin sie den Dünndarm besiedeln, der Mukosa anhaften und zu Würmern auswachsen. Die an der Dünndarmwand haftenden Parasiten (Würmer und Larven) saugen Blut aus den Darmzotten, wobei adulte Würmer 20-30 ml Blut pro Tag aufnehmen können. Durch diesen Blutverlust entsteht die 
Anämie. Die vom Weibchen im Dünndarm abgelegten Eier (Abb.5e) gelangen über den Stuhl in die Erde, wo sie sich zu Larven entwickeln.

Klinik. Am Ort des Eindringens entstehen juckende Papeln und Ulzerationen; eine bakterielle Superinfektion an der Eintrittsstelle kann vorkommen. Lungensymptome sind selten, hingegen entwickeln sich in der Folge gastrointestinale Symptome, deren Ausmaß von der Wurmmenge bestimmt wird. Unwohlsein, Nausea, Erbrechen und Bauchschmerzen, oft verbunden mit Gewichtsverlust, sind die häufigsten Symptome. Blutiger Durchfall oder Meläna können vorkommen. Die Folge des Blutverlusts ist eine Anämie.

Labordiagnostik. Die mikroskopische Untersuchung einer Stuhlprobe genügt, um die Wurmeier nachzuweisen. Es bestehen Bluteosinophilie und eine Eisenmangelanämie.

Therapie. Mebendazol $1 \times 300 \mathrm{mg} /$ Tag per os während 3 Tagen; alternativ: Albendazol $400 \mathrm{mg}$ als Einmaldosis per os [10].

Die Erreger der Ankylostomiasis besiedeln den Dünndarm und saugen dort Blut aus der Mukosa. Die Wurmeier können mikroskopisch in einer Stuhlprobe nachgewiesen werden.

\section{- Trichinose}

Epidemiologie und Übertragung. Der Erreger (Trichinella spiralis) kommt weltweit vor, ist aber in Mitteleuropa (Deutschland, Schweiz, Österreich) selten. Die Infektion erfolgt in der Regel durch infiziertes und nicht ausreichend erhitztes Wildfleisch (Wildschwein, Bär). Der Mensch ist ein Fehlwirt, da er nicht zur weiteren Fortpflanzung der Trichinen beiträgt. Akute Infektionen des Menschen mit Trichinella spiralis sind meldepflichtig.

Pathogenese. Die in Zysten verkapselten Larven werden im Magen oder Dünndarm freigesetzt, bohren sich in die Dünndarmmukosa und wachsen innerhalb von wenigen Tagen zu adulten Würmern, wonach die Paarung stattfindet. Im Dünndarm entsteht durch die Würmer eine starke Entzündung der Mukosa. Das Weibchen produziert eine Menge Larven, die durch die Mukosa des Dünndarms in den Körper penetrieren und via lymphatisches System oder Blutstrom in die Muskeln (Skelettmuskeln, Herzmuskel) und ins ZNS gelangen. Durch Abwehrreaktionen des Körpers (inklusive Verkalkungen) gelingt es den Larven, Jahre zu überleben.
Klinik. Die Krankheit verläuft in 3 Stadien:

- akute Gastroenteritis durch Schlucken der Larven (Hauptsymptome: Durchfall, Erbrechen, Abdominalkrämpfe)

- Larvenmigration: Kopfschmerzen, Myalgien, Fieber mit Lymphknotenschwellungen

- Zystenstadium: abhängig vom Ausmaß des Befalls (Muskeldysfunktionen, Myokarditis, Meningoenzephalitis, Schwindel)

Labordiagnostik. Die Diagnose erfolgt durch Larvennachweis in Muskelbiopsien. Serologische Tests sind hilfreich, bleiben aber nach Therapie noch monatelang positiv.

Therapie. Mebendazol 3×500 mg/Tag per os während 10-14 Tagen; alternativ: Albendazol $2 \times 400 \mathrm{mg} / \mathrm{Tag}$ per os während 10-14 Tagen [10].

Die Trichinose verläuft in 3 Stadien: akute Gastroenteritis, Larvenmigration und Zystenstadium. Der Larvennachweis erfolgt in Muskelbiopsien.

\section{Saugwürmer (Trematoden)}

\section{- Fasciola hepatica}

Epidemiologie und Übertragung. Der Erreger Fasciola hepatica oder Leberegel kommt weltweit vor und wird bis zu $3 \mathrm{~cm}$ lang. Er befällt vorwiegend Schafe und Rinder, wurde aber auch schon bei Hunden nachgewiesen. Die Infektion erfolgt während des Sommers und im Herbst auf der Weide. Seltene Infektionen beim Menschen werden durch infizierte Brunnenkresse, Löwenzahn oder selten durch befallenes Fallobst verursacht.

Nach Aufnahme nisten sich die infektiösen Larven im Dünndarm ein, durchwandern die Mukosa und gelangen in die Bauchhöhle. Von dort migrieren sie zur Leber, durchdringen die Leberkapsel und entwickeln sich im Lebergewebe zu geschlechtsreifen Würmern. Sie wandern dann in die Gallenwege ein, wo die Eiablage beginnt. Die Eier werden dann über den Stuhl wieder ausgeschieden. Sie wachsen im Wasser, werden von Schnecken aufgenommen, wo sie über mehrere Zwischenstufen zur infektiösen Larve heranwachsen und die Pflanzen besiedeln, worauf der Zyklus von Neuem beginnen kann.

Klinik. Die Hälfte der Infektionen verläuft subklinisch. Die wichtigsten Symptome sind abdominale Schmerzen, intermittierendes Fieber, allgemeines Unwohlsein und Gewichtsverlust. Cholangitiden sind möglich. Ein 
typischer klinischer Befund ist eine Hepatomegalie. Laborchemisch findet man Zeichen der Cholestase.

Labordiagnostik. Die Diagnose erfolgt durch Wurmeiernachweis im Nativstuhl oder in der Galle. Oft sind mehrere Proben notwendig. Es bestehen Eosinophilie und schwere Anämieformen (vor allem bei Kindern).

Therapie. Triclabendazol $10-12 \mathrm{mg} / \mathrm{kg}$ KG/Tag per os während 2 Tagen [10].

Fasciola hepatica entwickeln sich im Lebergewebe zu geschlechtsreifen Würmern. Die Hälfte der Infektionen verläuft asymptomatisch, typische Befunde sind Hepatomegalie und Cholestasezeichen.

\section{- Schistosomiasis}

Epidemiologie und Übertragung. Die Erreger (Schistosoma mansoni und Schistosoma japonicum oder Pärchenegel) sind in den Tropen und Subtropen lebende, zu den Saugwürmern gehörende Parasiten. Weltweit sind über 80 verschiedene Arten bekannt. Ursprünglich wurde die Erkrankung nach dem Entdecker Theodor Bilharz als Bilharziose benannt, doch wird heute nur noch der Name Schistosomiasis verwendet. Schistosoma sind die einzigen Saugwürmer, die getrenntgeschlechtlich vorkommen, wobei sich Männchen und Weibchen morphologisch klar unterscheiden. Schistosoma mansoni, der wichtigste Erreger der Infektion (Abb.5f), kommt auf dem ganzen afrikanischen Kontinent vor, während Schistosoma japonicum vor allem in China und Japan nachgewiesen wird.

Lebenszyklus. Schistosoma befallen Säugetiere, Vögel und Krokodile, wobei insbesondere das Gefäßsystem betroffen ist. Die Ausscheidung von Eiern erfolgt über Harn und Stuhl des befallenen Tieres. Die Eier entwickeln sich zu Larven und dringen in einen Zwischenwirt ein (in der Regel eine Schnecke). In den Schnecken entwickeln sich die Parasiten zu Sporozysten und gelangen dann ins Wasser, wo sie einen geeigneten Endwirt finden müssen. Bei Kontakt mit einem geeigneten Wirt durchdringen die Sporozysten die Haut und gelangen in die Blutbahn, wo sie sich zum geschlechtsreifen Wurm entwickeln. Zur Paarung wandern die Würmer in die Pfortader.

Pathogenese. Die adulten Würmer ernähren sich von Blutbestandteilen, sind aber für den Wirt unschädlich. Die klinischen Konsequenzen werden durch die Wurmeiner verursacht. Diese rufen eine Entzündungsreaktion in den Venen hervor (häufig sind die Splanch- nikusvenen betroffen), die Gefäße werden durchlässig und die Eier können in Darm und Harnblase gelangen. Beim Gewebedurchtritt bewirken die Eier eine entzündliche Reaktion und nisten sich zunächst in der Blasenwand oder in der Darmwand ein. Sie können das Gewebe dann in Richtung Blasen- oder Darmlumen durchdringen und werden mit dem Urin oder dem Stuhl ausgeschieden. Andere betroffene Systeme sind Leber, Niere und Gehirn, wodurch die entsprechenden klinischen Symptome verursacht werden.

Klinik. Die ersten Symptome sind Juckreiz an der Eintrittspforte mit Bildung eines Hautausschlages. Der Erreger wandert dann durch das Gewebe und gelangt in die Lunge, was 4-8 Wochen später eine allergische Reaktion mit Husten und Fieber auslösen kann (Katayama-Fieber). Da die Schistosomen über Jahre hinweg überleben können und fortlaufend Eier legen, kann es in der Blase zu einer chronischen Entzündung kommen, was Grundlage für die Entwicklung eines Blasenkrebses sein kann. Schistosomiasis gilt deshalb als Präkanzerose. Schistosomenarten, die primär Leber und Milz befallen, führen zu Leberzirrhose und Splenomegalie mit den entsprechenden potenziellen Komplikationen. ZNS-Befall ist selten.

Labordiagnostik. Die Diagnose erfolgt durch Wurmeiernachweis im Nativstuhl. Ein serologischer Test ist vorhanden, doch bleibt dieser auch nach Therapie noch längere Zeit positiv.

Therapie. Praziquantel $60-75 \mathrm{mg} / \mathrm{kg}$ KG per os als Einzelgabe, aufgeteilt in 2-3 Dosen; Therapie nach 2 Monaten evtl. wiederholen. $20 \mathrm{mg}$ Prednison per os pro Tag bei Katayama-Fieber [10].

Schistosomen können zu einer chronischen Entzündung der Blase führen, weshalb die Schistosomiasis als Präkanzerose für Blasenkrebs gilt.

\section{Cestoden}

\section{Taeniasis saginata}

Epidemiologie und Übertragung. Der Rinderbandwurm (Erreger Taenia saginata) ist ein Parasit im Darm des Menschen; als Zwischenwirt dienen Rinder. Die weltweite Inzidenz des Rinderbandwurms wurde durch die Rinderzucht hervorgerufen und ist größer als diejenige des Schweinebandwurms [8]. 
Lebenszyklus. Die Infektion kommt zustande, wenn eine genügend große Menge an ungekochtem oder zu wenig gekochtem infiziertem Rindfleisch konsumiert wird. Die Larven lagern sich an die Mukosa des Dünndarms an, wo sie sich zu adulten Würmern entwickeln. Der adulte Wurm kann bis $25 \mathrm{~m}$ lang werden und 2000 Proglottiden (Abb.7) enthalten. Die Proglottiden werden mitsamt den Eiern (Abb.5c) im Stuhl ausgeschieden und von den Rindern aufgenommen, bei denen sie sich im Muskelgewebe (Zwerchfell, Herz) ansiedeln. Sie bleiben im Rind, und diese Form der Erkrankung wird Zystizerkose genannt. In vielen Ländern wird Rindfleisch in einer gesetzlich vorgeschriebenen Fleischbeschau durch einen Tierarzt kontrolliert, sodass Krankheitsfälle bei uns sehr selten vorkommen. Eine humane Zystizerkose mit T. saginata ist eine Rarität.

Klinik. Die intestinale Form mit adultem Wurm ist in der Regel asymptomatisch. Selten entstehen Komplikationen: Appendizitis oder intestinale Obstruktionen.

Labordiagnostik. Die Diagnose wird durch den mikroskopischen Nachweis von Eiern oder Proglottitiden im Stuhl gestellt. Eine Bluteosinophilie ist in der Regel vorhanden.

Therapie. Praziquantel $10-20 \mathrm{mg} / \mathrm{kg}$ per os als Einmaldosis; alternativ: Niclosamid $2 \mathrm{~g}$ per os als Einmaldosis. 2 Stunden nach Tabletteneinnahme wird ein Laxativum empfohlen (Magnesiumsulfat), um den Wurm möglichst rasch und vollständig zu eliminieren [10].

\section{- Taeniasis solium}

Epidemiologie und Übertragung. Der Schweinebandwurm (Taenia solium) ist ein Parasit des Darmes des Menschen, als Zwischenwirt dienen Schweine. Der Schweinebandwurm kann zwei verschiedene Infektionsformen beim Menschen hervorrufen: eine intestinale Infektionsform mit dem adulten Wurm und die Zystizerkose, eine Gewebserkrankung, verursacht von den Larven des Wurmes.

Lebenszyklus. Eine intestinale Infektion kann entstehen, wenn ungekochtes oder zu wenig gekochtes Schweinefleisch konsumiert wird, das mit Larven infiziert ist. Die Larven lagern sich an die Mukosa des Dünndarms an, wo sie sich zu adulten Würmern entwickeln. Der adulte Wurm kann bis $7 \mathrm{~m}$ lang werden und 1000 Proglottiden enthalten. Die Proglottiden werden mitsamt den Eiern im Stuhl ausgeschieden, die Eier in der Folge von den Schweinen gefressen, bei denen sie sich im Muskelgewebe zu Larven entwickeln

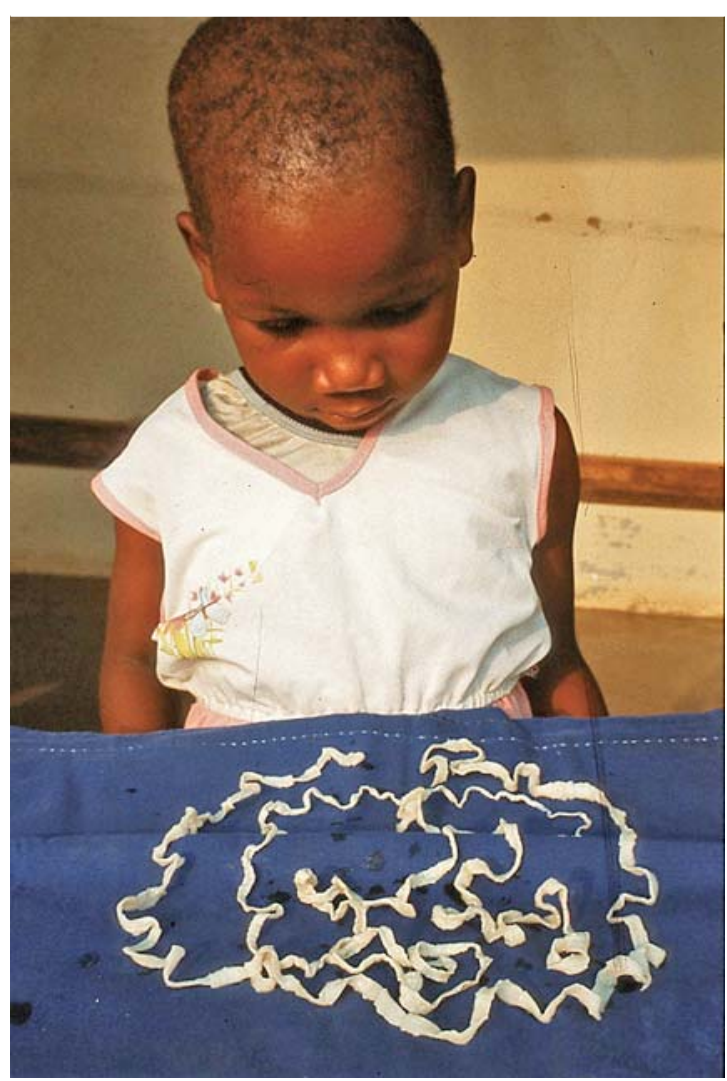

Abb. 7 Taenia saginata. Patient nach Abgang eines Rinderbandwurmes (aus Riemann, Fischbach, Galle, Mössner: Gastroenterologie in Klinik und Praxis. Stuttgart: Thieme).

und zur Zystizerkose führen. Anders als beim Rinderbandwurm kann der Mensch auch als Zwischenwirt dienen: Wenn vom Menschen Eier geschluckt werden, entwickeln sich diese im Darm zu Larven, penetrieren die Mukosa und können in der Folge alle Organe befallen und dort Zysten bilden. Am häufigsten betroffen sind die Subkutis, Muskeln, Gehirn, Augen, Herz, Lunge und Leber.

Klinik der intestinalen Form. Die intestinale Form mit adultem Wurm ist in der Regel asymptomatisch. Selten entstehen Komplikationen: Toxische Metabolite des Wurms können neurologische Symptome erzeugen oder der Wurm perforiert den Dünndarm, was zu einer Peritonitis führen kann. Falls der Mensch als Zwischenwirt dient, siedeln sich die Finnen in Muskeln (Skelettmuskeln, Zwerchfell, Herz), aber auch im Gehirn an. Seitens des ZNS entstehen unspezifische Symptome (Kopfschmerzen), neurologische Ausfälle und entzündliche Reaktionen (s. unten).

\section{Labordiagnostik der intestinalen Form. Die Diagnose} wird durch den mikroskopischen Nachweis von Eiern oder Proglottitiden im Stuhl gestellt. Neuerdings steht auch ein spezifischer ELISA-Test zur Verfügung, der den Nachweis eines spezifischen Antigens im Stuhl erlaubt. Bluteosinophilie ist in der Regel vorhanden. 
Therapie der intestinalen Form. Praziquantel 10 - $20 \mathrm{mg} / \mathrm{kg}$ KG per os als Einmaldosis; alternativ: Niclosamid $2 \mathrm{~g}$ per os als Einmaldosis. 2 Stunden nach Tabletteneinnahme wird ein Laxativum empfohlen (Magnesiumsulfat), um den Wurm möglichst rasch und vollständig zu eliminieren.

Klinik der Zystizerkose. Die Zystizerkose hat einen anderen klinischen Verlauf. Solange die Larven leben, liegen keine oder nur minimale Symptome vor. Sobald die Larven aber absterben, entwickelt sich eine starke Abwehrreaktion des Wirtorganismus mit Fibrose und Sklerosierung. Dadurch können extensive Gewebsdestruktionen entstehen. Seitens des ZNS kommt es zu neurologischen Defiziten mit epileptischen Anfällen, Synkopen und Ausbildung eines Hydrozephalus. Die Symptome sind primär abhängig vom befallenen Organ.

Diagnostik der Zystizerkose. Die verkalkten Zysten können durch bildgebende Verfahren dokumentiert werden: Je nach Organ bieten sich Ultraschall, Computertomografie oder eine MRT-Untersuchung an. Die genaue Diagnose erfolgt histologisch. Seit Kurzem steht ein hochspezifischer und sensitiver enzymgebundener Elektrotransfer-Immunoblot-Assay zur Verfügung, der eine genaue Diagnose ermöglicht. Eine Bluteosinophilie ist wie bei der intestinalen Form in der Regel vorhanden.

Therapie der Zystizerkose. Die Therapie ist, wenn immer möglich, operativ durch chirurgische Entfernung der Zysten, gefolgt von einer medikamentösen Behandlung mit Albendazol $2 \times 400 \mathrm{mg} /$ Tag per os für 14 Tage. Praziquantel $3 \times 50 \mathrm{mg} / \mathrm{kg}$ KG per os während 14 Tagen wird auch verwendet, scheint aber weniger wirksam zu sein als Albendazol [10].

Je nachdem, ob Larven oder Eier des Schweine-

bandwurms vom Menschen aufgenommen werden, entwickelt sich eine meist asymptomatische intestinale Form oder eine Zystizerkose, die möglichst chirurgisch und im Anschluss medikamentös

behandelt werden sollte.

\section{Diphyllobothriasis}

Epidemiologie und Übertragung. Der Fischbandwurm (Diphyllobothrium latum) ist ein Parasit des Darmes des Hundes, sehr selten der Hauskatze und des Menschen. Als Zwischenwirt dienen Krebse oder Fische, die sich von Plankton ernähren. Der Erreger kommt vor allem in Nord- und Südamerika, in Europa und Teilen Asiens vor. Die Infektion tritt vorwiegend in Gegenden auf, wo roher oder nicht ausreichend erhitzter mit Larven verseuchter Fisch konsumiert wird.

Lebenszyklus. Die Larven lagern sich an die Mukosa des Dünndarms an, wo sie sich zu adulten Würmern entwickeln. Der adulte Wurm kann bis $20 \mathrm{~m}$ lang werden und 4000 Proglottiden enthalten. Die Proglottiden werden mitsamt den Eiern im Stuhl ins Wasser ausgeschieden; im frischen Wasser entwickeln sich die Eier innerhalb von 2 Wochen zu Larven. Diese werden von geeigneten Zwischenwirten gefressen. Die infizierten Zwischenwirte werden in der Folge von den Fischen gefressen, womit der Lebenszyklus komplett ist.

Klinik. Die Infektion ist in der Regel asymptomatisch. Selten können unspezifische Bauchschmerzen und Durchfall auftreten. In gewissen Gegenden (z. B. Finnland) sind perniziöse Anämien beschrieben worden (Kompetition zwischen Wirt und Wurm um das vorhandene Vitamin $B_{12}$ ).

Diagnostik. Die Diagnose wird durch den mikroskopischen Nachweis von Eiern oder Proglottiden im Stuhl gestellt. Eine Bluteosinophilie ist wie bei der intestinalen Form in der Regel vorhanden.

Therapie. Praziquantel $10-20 \mathrm{mg} / \mathrm{kg}$ KG per os als Einmaldosis; alternativ: Niclosamid $2 \mathrm{~g}$ per os als Einmaldosis [10].

Interessenkonflikt: Der Autor erklärt, dass kein Interessenkonflikt vorliegt. 


\section{Über den Autor}

\section{Christoph Beglinger}

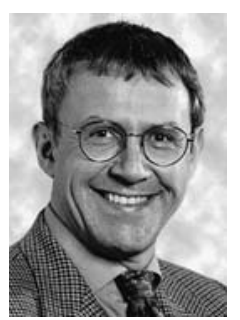

Prof. Dr. med., Jahrgang 1950, Medizinstudium in Bern und Montpellier, danach Assistenzarzt in der Abteilung für Anästhesie, Kantonsspital Bruderholz, und in den Abteilungen für Innere Medizin, Nephrologie sowie Gastroenterologie, Universitätsspital Basel. Forschungsaufenthalt am Center for Ulcer Research and Education in Los Angeles, USA. 1989-1999 Leitender Arzt der Abteilung für Gastroenterologie, Universitätsspital Basel, 1999-2011 Ärztlicher Leiter der Abteilung. Seit 2011 Dekan der Medizinischen Fakultät der Universität Basel. Rubrikenherausgeber der Gastroenterologie up2date für Infektionskrankheiten des Magen-Darm-Trakts.

\section{Korrespondenzadresse}

Prof. Dr. Christoph Beglinger

Klinik für Gastroenterologie und Hepatologie

Universitätsspital

Petersgraben 4

4031 Basel

Schweiz

E-Mail: beglinger@tmr.ch

\section{Kernaussagen}

- Parasitosen des Gastrointestinaltraktes werden durch Protozoen (Einzeller) und Helminthen verursacht.

- Viele Parasitosen werden verzögert erkannt und diagnostiziert, weil nicht an sie gedacht wird.

- Die Übertragung erfolgt in der Regel durch kontaminierte Nahrungsmittel oder verseuchtes Wasser, aber auch von Mensch zu Mensch oder von Tier zu Mensch. Speziell Kinder und immunsupprimierte Personen sind vermehrt betroffen.

\section{Protozoen}

- Es gibt zwei Formen der Amöbeninfektion: die pathogene Form mit E. histolytica und die nicht pathogene Form mit E. dispar. Mikroskopisch können die beiden Formen nicht unterschie- den werden, nur durch spezifische ELISA-Methoden.

- Kokzidien (Cryptosporidium parvum, Isospora belli, Mikrosporidien) sind Protozoen, die sowohl beim Tier als auch beim Menschen verschiedene Krankheiten erzeugen können.

\section{Helminthen}

- Nematoden, die eine Lungenpassage durchmachen, sind Ascaris lumbricoides, Ancylostoma duodenale und Strongyloides stercoralis. Keine Lungenpassage brauchen Enterobius vermicularis, Trichuris trichiura und Trichinella spiralis.

- Labordiagnostik ist notwendig zum Erregernachweis (in der Regel im Stuhl).

- Die Therapie ist abhängig vom Erreger.

\section{Literatur}

1 Gasbarre LC. Effects of gastrointestinal nematode infection on the ruminant immune system. Vet Parasitol 1997; 72: 327 337; discussion 337-343

2 The European Union Summary Report on trends and sources of zoonoses, zoonotic agents and foodborne outbreaks in 2012, European Food Safety Authority (EFSA), European Centre for Disease Prevention and Control. EFSA Journal 2014; 12 : 3547

3 Koski KG, Scott ME. Gastrointestinal nematodes, nutrition and immunity: breaking the negative spiral. Annu Rev Nutr 2001; 21: $297-321$

4 Lawrence CE. Is there a common mechanism of gastrointestinal nematode expulsion? Parasite Immunol 2003; 25: 271 281

5 Gupta YK, Gupta M, Aneja S et al. Current drug therapy of protozoal diarrhoea. Indian J Pediatr 2004; 71: 55 - 58

6 Bradley JE, Jackson JA. Immunity, immunoregulation and the ecology of trichuriasis and ascariasis. Parasite Immunol 2004; 26: $429-441$

7 Else KJ. Have gastrointestinal nematodes outwitted the immune system? Parasite Immunol 2005; 27: 407 - 415

8 Magambo J, Njoroge E, Zeyhle E. Epidemiology and control of echinococcosis in sub-Saharan Africa. Parasitol Int 2006; 55 : 193 - S195

9 Gascon J. Epidemiology, etiology and pathophysiology of traveler's diarrhea. Digestion 2006; 73 : $01102-108$

10 Majer S, Neumayr A. Parasiten des Gastrointestinaltraktes. Schweizerisches Medizinforum 2015; 15: 242 - 250 


\section{CME-Fragen}

\section{CME•thieme.de}

\section{CME-Teilnahme}

- Viel Erfolg bei lhrer CME-Teilnahme unter http://cme.thieme.de

Diese Fortbildungseinheit ist 12 Monate online für eine CME-Teilnahme verfügbar.

- Sollten Sie Fragen zur Online-Teilnahme haben, unter http://cme.thieme.de/hilfe finden Sie eine ausführliche Anleitung.

1 Wie werden Askariden (Ascaris lumbricoides) nachgewiesen?
A Blutserologie
B Endoskopie mit Histologie
C PCR-Methode
D Stuhl nativ; Mikroskopie
E durch keine der genannten Methoden

2 Welche Behandlung ist geeignet für Patienten mit akuter Amöbenkolitis?
A Amoxicillin
B Probiotika
C Loperamid
D 5-Nitroimidazol-Präparate
E keines der genannten Medikamente

3 Wodurch erfolgt die Übertragung der Chagas-Erkrankung?
A verschmutztes Wasser
B ungenügende Analhygiene
C Tröpfcheninfektion
D Insektenstiche
E Schwimmen in tropischen Flüssen

4 Welches der genannten Charakteristika trifft nicht für Giardia lamblia zu?
A Gewichtsverlust
B Bauchschmerzen
C asymptomatische Verläufe
D resistent gegen übliche Wasseraufbereitung
E Bluteosinophilie
A Giardiose
B Askariasis
C Schistosomiasis
D Trichuriasis
E Kryptosporidiose 


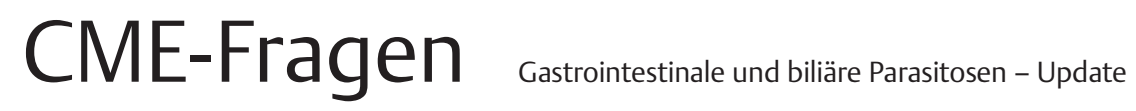

6 Welche parasitäre Infektion gilt als Präkanzerose?
A Oxyuriasis
B Blastozystose
C Trichuriasis
D Schistosomiasis
E keine der genannten Infektionen

7 Welche der folgenden Aussagen zur Amöbiasis ist falsch?
A Obwohl die Trophozoiten den Dickdarm kolonisieren, ist eine invasive Amöbenerkrankung relativ selten.
B Die Amöben produzieren Toxine, die im Wirt zu Destruktion der Mukosa führen.
C Amöbenabszesse entwickeln sich in der Regel durch Penetration der Amöben vom Darm in die Leber via Portalsystem.
D Eine invasive Amöbiasis entsteht häufig nach erfolgreicher Therapie eines Leberabszesses.
E Eine akute Amöbenerkrankung ist charakterisiert durch blutige Durchfälle und Bauchschmerzen.

8 Welche der folgenden Aussagen zu Strongyloides stercoralis ist falsch?
A Strongyloides stercoralis kommt in der gesamten tropischen und subtropischen Region vor.
B Die Penetration infektiöser Larven erfolgt durch die Haut.
C Bei Strongyloides stercoralis hängen die intestinalen Komplikationen von der Parasitenmenge und dem Immunstatus ab.
D Die disseminierte Strongyloidose kommt vermehrt nach Steroidtherapie vor.
E Strongyloides stercoralis kann oral-fäkal übertragen werden.

$9 \quad$ Was gilt nicht für Strongyloides stercoralis?
A Eiablage in der Mukosa des Dünndarms
B vor allem bei Migranten aus Südostasien oder Afrika
C asymptomatischer Verlauf möglich
D reaktive Arthritiden bei länger bestehenden Infektionen
E Überlebenszeit der Würmer im Menschen maximal 2 Jahre

10 Welche Aussage zu Mikrosporidien ist falsch?
A Die Diagnose erfolgt durch Stuhluntersuchung.
B Die Übertragung erfolgt fäkal-oral durch infizierte Patienten oder kontaminiertes Trinkwasser und Nahrungsmittel.
C Es kommt zu einem schweren Verlauf bei Immunsuppression.
D Bei Immunsupprimierten können eine akute Cholezystitis und eine sklerosierende Cholangitis auftreten.
E Die Therapie besteht in Albendazol $400 \mathrm{mg}$ als Einmaldosis. 